\title{
Research on technology of data link fusion about UAV used on inspection for Power transmission line
}

\author{
Cui Zhi mei ${ }^{1, \mathrm{a}}$, Huang Zhi du ${ }^{1, \mathrm{~b}}$ \\ ${ }^{1}$ Electric Powe Research Institute of Guangxi Power grid Co., Ltd, Guangxi Nanning 530023
}

\begin{abstract}
UAV is so small and flexible that plays an important role in inspection for Power transmission line, especially at the voltage of $110 \mathrm{kV}, 220 \mathrm{kV}, 500 \mathrm{kV}$ and so on. Coupled with the development of UAV autonomous intelligent inspection technology, the personnel who should inspect the Power transmission line need not to across mountains or climb up to the power transmission towers to inspect the insulators and other equipment manually, so it has been widely used in the inspection for Power transmission line. The stable controlling of UAV flight is and the data link fusion is the basic guarantee of multiple UAV cluster operation. this paper bases on the mode of cluster operation and analyzing the technology of data link fusion, then puts forward single to multiple mode of Data fusion in RTK, which provides an important reference for the research of multiple UAV cluster operation about inspection.
\end{abstract}

\section{Introduction}

Unmanned aerial vehicle (UAV) which is used for Power transmission line inspection has the characteristics of Portable and flexible and so on ${ }^{[1]}$. The personnel who needs to complete the task of inspecting Power transmission line do not need to wade through mountains or climb up to the Power transmission line tower to inspect the insulator, conductor line or other equipment attached to the body of Power transmission line manually, whats more, The development of autonomous intelligent inspection technology used in UAV makes inspection for the Power transmission line more efficiency, it has been widely used in the State Grid and China Southern Power Grid .

The data link of UAV which is used for Power transmission line inspection is an important part in the UAV system ${ }^{[2]}$, which is mainly reflected in the association between the body of UAV and the station of ground, mainly including graph transmission and data transmission and other data channels.

At present, the mode of the modulation used in the system is relatively single, such as $2 \mathrm{FSK}$ and BPSK, the rate of transmission and the ability of anti-interference are relatively weak ${ }^{[3-5]}$. But more and more instructions should be transmitted with the needs of intelligence and refinement which is used in Power transmission line inspection, so the research about improving the level of data link should mainly focus on the rate of transmission and the ability of anti-interference.

In this paper, we use the system of integrated data link based on the theory of Single-Carrier Frequency-Domain Equalization (SC-FDE) into RTK communication function which is used on Multiple UAV cluster flying commission, and it can provide reliable communication which is used in Multiple UAV cluster flying commission for inspection about Power transmission line.

\section{Research status of data link about UAV}

At present, the most commonly data link system about UAV which is used for Power transmission line inspection in China is the data link used for navigation system when in the early $1980 \mathrm{~s}^{[6]}$. This system is composed by the equipment of airborne and ground placement. The rate of data can reach $600 \mathrm{bps}$, and the mode of the modulation is ASK. it sends out instructions with address code from the ground-station, and the UAV receives the broadcast instructions from ground according to the address. After receiving the command, it will complete the command and return the processed instructions to the ground within a certain time delay, UAV receives the instructions which is translated and coded, and then convert it into voice instructions through the coder. This defect of the link is that it can't transmit voice instructions, the rate of data is more lower, so does the ability of anti-interference, whats worse, the ground-station is vulnerable to be attacked.

The United States has developed varieties of tactical data links and started to improve other style about data links. But the main data link used by the U.S. is still link4A system, as shown in Figure 1 and Figure 2, it includes the equipment of UHF radio, modem, the equipment of cryptogram, the equipment of data processor and user interface. It conforms to the specification of data link, and it is composed of the transmission about Half duplex (UHF), control station and controlled station. 


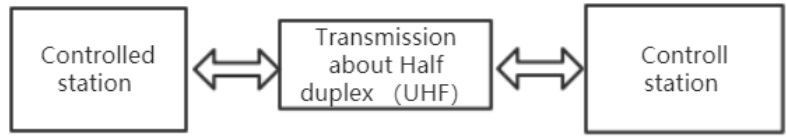

Figure 1. link4a system architecture

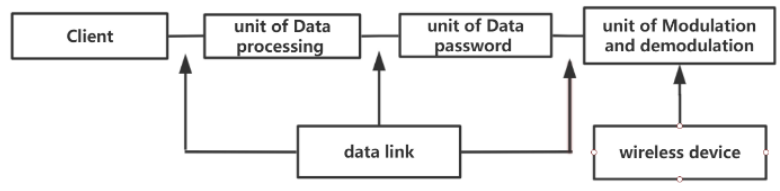

Figure 2. UHF half duplex Terminal Architecture

The system of Link4A can link different unit instructions in a single channel by multiple addresses when it is used. The instructions is transmitted mainly by the style of time-division sequence. The instruction which comes from control station is usually called control instructions, and the instruction which is fed-backed to the control station is called response instructions. In the process of using this system, both the control station and the controlled station are by the mode of half duplex, but the control station must have the function of full duplex operation.

The equipment of data terminal about the ground control station provides computer used for the data system, the interface between radio equipment used for the system of sending and receiving control instructions, so as to the response instructions. The terminal equipment of the control station can verify the navigation of UAV by this system, and the transmission of the data is unidirectional, The terminal equipment of the control station can operate with special time, that is to say it can generate a cycle of about $14 \mathrm{~ms}$ which is used for sending instructions, but it can only generate a cycle of about $2 \mathrm{~ms}$ which is used for receiving instructions. As for the time interval required by processing or detecting the control instructions, the terminal equipment of the control station can also network the system and detect the error which is generated by the control signal.

In our country, the main research on UAV is more focused on the transmission for image and the stability control, while the research on UAV the mode of communication is poor. At present, it is still in the stage of learning and testing. Whats worse, the research on data link fusion for communication technology about UAV used in Power transmission line inspection is less.

\section{Technology of UAV data link fusion in power transmission inspection.}

The development of data link fusion technology rapidly promotes the UAV used for Power transmission line inspection to intellectualization, but the driving of UAV highly depends on the remote control system. Data link fusion system used for UAV makes Power transmission line inspection more practical. The data link has bidirectional mechanism, which is divided into uplink and downlink. The uplink data link is mainly responsible for flight control of the UAV used for Power transmission line inspection, while the downlink data link is mainly responsible for monitoring the UAV used for Power transmission line inspection. The system of two-way channel data link fusion makes the UAV more efficient, so as to the ability of anti-interference. This mode can reduce the cost labor and the loss out of control about UAV used for Power transmission line inspection greatly, so it can provide reliable technical support for the mode of multiple UAV cluster operation used for Power transmission line inspection.

\section{Data link convergence}

UAV used for Power transmission line inspection is a kind of aircraft operation controlled by sending and receiving instructions on wave radio and programmer. It is mainly composed of ground station and front ending, the front ending of UAV is composed by control system and pod. The communication between the front ending and the terminal is realized by wireless broadcast link of the communication. The link of wireless communication is responsible for receiving the control command data which is sent by the ground terminal, while the sensors on the airborne system are responsible for measuring the motion parameters and GPS from UAV, then transmit them to the airborne control computer, and the computer outputs the control commands to the relevant equipment, so as to realize various functions of the command and control about UAV used for Power transmission line inspection.

\section{1 composition of ground station measurement and control system}

The ground measurement and control system of UAV is mainly composed of central processing, human-computer interaction, wireless communication, command acquisition and command center. The functional architecture is shown in the figure 3.



Figure 3. architecture of UAV Ground Measurement and control system

\section{2 hardware composition of airborne terminal}

The airborne control system is mainly composed of radio signal receiver and airborne data control board, it includes the data of uplink and downlink used for controlling, it also connects with flight control device and pod device about UAV. The uplink data part is used to receive the uplink data sent by the radio station, then analyze this instructions. The downlink data control part is used to receive the remote control instructions and the downlink 
task instructions fed back from flight control and pod device, and encode them together. Then the data of the video and image are sent to the radio station as a broadcast signal. After receiving the data, the radio sends it to the serial port of the uplink data control part, receives the data of the downlink data control part and continue to send the monitoring information. The flight control device returns information of the serial port from uplink data control part, and the pod device receives the remote controlling command through the serial port from the controlling part of uplink data.

\section{Technology of Data link fusion for multiply UAV cluster control}

The technology of data link about one station to multiple machine on UAV used for Power transmission line inspection refers to the data link communication between a ground station to multiple UAV, It uses frequency division, time division and code division access to distinguish telemetry parameters and mission sensor information from different UAV. This mode simplifies the quantity of ground control station equipment, only uses one ground station to control multiple UAV, it also improves the ability of interconnection, makes UAV realize the compatibility and cooperative work of multiple machine and system. Whats more, it improves the efficiency of measurement and control system on UAV used for Power transmission line inspection.

To realize the generalization and interactivity of UAV, we must first realize the generality of data link in physical layer, including the unification of measurement and control communication system such as frequency band, signal format and data format, which is the basis of all interconnection. In order to realize the interactivity between data link terminals and make the image and management data transmitted from the air, it should be distributed through the link data terminal, it is also necessary to accurately describe the general requirements of data link about broadband, system function, interface and its characteristics, security requirements, link management, communication protocol and other general technical specifications required by interactivity, so as to improve the generalization and reliability of the system .

Each UAV needs to establish the following links like table 1to realize the cluster control mode of one station to multiple UAV:

Table 1: Requirements of speed about data transmission

\begin{tabular}{|c|c|c|c|}
\hline Name & $\begin{array}{c}\text { Uplink } \\
\text { data }\end{array}$ & $\begin{array}{c}\text { downlink } \\
\text { data }\end{array}$ & remarks \\
\hline $\begin{array}{c}\text { Remote } \\
\text { control }\end{array}$ & $<1 \mathrm{kB} / \mathrm{s}$ & 0 & $<100 \mathrm{~ms}$ \\
\hline $\begin{array}{c}\text { Flight } \\
\text { control }\end{array}$ & $<1 \mathrm{kB} / \mathrm{s}$ & $1 \sim 4 \mathrm{kB} / \mathrm{s}$ & Diplexer \\
\hline $\begin{array}{c}\text { Image } \\
\text { quality }\end{array}$ & 0 & $4 \mathrm{MB} / \mathrm{s}$ & high bandwidth \\
\hline RTK & $<0.5 \mathrm{kB} / \mathrm{s}$ & 0 & $\begin{array}{c}\text { No special } \\
\text { requirements }\end{array}$ \\
\hline
\end{tabular}

The data link fusion technology can fully apply to the control of multiple UAV used for Power transmission line inspection. There are five alternative combination schemes, as shown in the table2.

Table2.alternative combination schemes

\begin{tabular}{|c|c|c|c|c|c|}
\hline $\begin{array}{l}\mathrm{N} \\
\mathrm{O} .\end{array}$ & $\begin{array}{l}\text { Remote } \\
\text { control }\end{array}$ & $\begin{array}{l}\text { Flight } \\
\text { control }\end{array}$ & image & RTK & $\begin{array}{c}\text { Lin } \\
k\end{array}$ \\
\hline 1 & $\begin{array}{c}\text { 1 controll } \\
\text { er*N }\end{array}$ & $\mathrm{p} 2 \mathrm{p} * \mathrm{~N}$ & $\mathrm{p} 2 \mathrm{p} * \mathrm{~N}$ & $\begin{array}{c}\text { Transmissi } \\
\text { on of } \\
\text { Broadcast } \\
\text { data }\end{array}$ & $\begin{array}{l}4^{*} \\
\mathrm{~N}\end{array}$ \\
\hline 2 & $\begin{array}{c}\text { 1 controll } \\
\text { er*N }\end{array}$ & $\begin{array}{c}\text { Ensemble } \\
\text { of Image } \\
\text { and } \\
\text { digital } \\
\text { based on } \\
4 \mathrm{G}^{*} \mathrm{~N}\end{array}$ & $\begin{array}{c}\text { Ensemble } \\
\text { of Image } \\
\text { and digital } \\
\text { based on } \\
4 \mathrm{G}^{*} \mathrm{~N}\end{array}$ & $\begin{array}{c}\text { Transmissi } \\
\text { on of } \\
\text { Broadcast } \\
\text { data }\end{array}$ & $\begin{array}{l}3^{*} \\
\mathrm{~N}\end{array}$ \\
\hline 3 & $\begin{array}{l}\text { Ensembl } \\
\mathrm{e} \text { of } \\
\text { Image } \\
\text { and } \\
\text { digital } \\
{ }^{*} \mathrm{~N}\end{array}$ & $\begin{array}{c}\text { Ensemble } \\
\text { of Image } \\
\text { and } \\
\text { digita*N }\end{array}$ & $\begin{array}{c}\text { Ensemble } \\
\text { of Image } \\
\text { and } \\
\text { digita*N }\end{array}$ & $\begin{array}{c}\text { Ensemble } \\
\text { of Image } \\
\text { and } \\
\text { digita*N }\end{array}$ & $\begin{array}{l}1^{*} \\
\mathrm{~N}\end{array}$ \\
\hline 4 & $\begin{array}{c}1 \text { controll } \\
\text { er*N }\end{array}$ & $\begin{array}{c}\text { Net of } \\
\text { Image and } \\
\text { digital }\end{array}$ & $\begin{array}{c}\text { Net of } \\
\text { Image and } \\
\text { digital }\end{array}$ & $\begin{array}{c}\text { Net of } \\
\text { Image and } \\
\text { digital }\end{array}$ & $\begin{array}{l}1+ \\
\mathrm{N}\end{array}$ \\
\hline 5 & $\begin{array}{l}\text { Net of } \\
\text { Image } \\
\text { and } \\
\text { digital }\end{array}$ & $\begin{array}{c}\text { Net of } \\
\text { Image and } \\
\text { digital }\end{array}$ & $\begin{array}{c}\text { Net of } \\
\text { Image and } \\
\text { digital }\end{array}$ & $\begin{array}{c}\text { Net of } \\
\text { Image and } \\
\text { digital }\end{array}$ & 1 \\
\hline
\end{tabular}

It can be seen that 4 and 5 is the optimal scheme from the above comparison table. If the delay of remote control signal transmission can be controlled within $100 \mathrm{~ms}$, scheme 5 is the optimal scheme. As shown in the figure, taking $4 \mathrm{UAV}$ as an example, the terminal collects and fuses the front-ending data link of single UAV and carries out transmission and processing about data, which greatly reduces the power consumption of the processor.

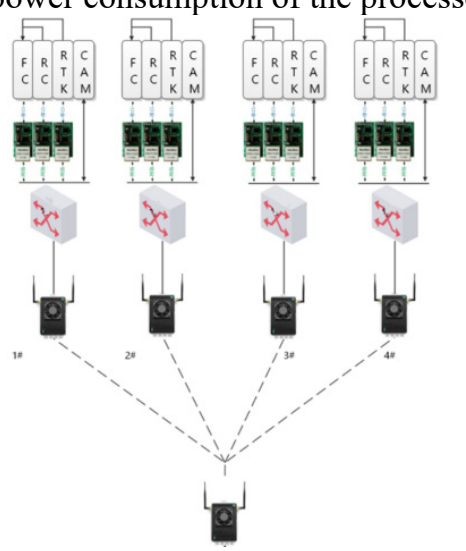

Figure 4. RTK Data Link diagram of multiple UAV

In addition to the above technology of high-speed data transmission, if the operating distance is longer, the ground station needs to use the directional tracking antenna with higher gain. Multiple antennas or multiple beam antennas should be used when the antenna beam 
cannot cover multiple UAV at the same time. The ground station generally adopts directional antenna or wide beam antenna when there is no need for mission sensor information transmission. At this time, the data link fusion technology can reduce the power consumption of data transmission caused by long distance to a greater extent, whats more, using data fusion technology can also improve the stability of flight control, cause there is no need to specify the link data separately.

\section{Conclusion}

The simultaneous inspection of multiple UAV used for Power transmission line inspection effectively improves the performance about the data of Power transmission line inspection. At the same time, a single operation can solve the inspection task of multiple sections near the Power transmission line. The data link fusion technology about $\mathrm{UAV}$ on graph transmission and data transmission changes single data channel to many data fusion. It provides basic guarantee mechanism for multiple UAV cluster operation on Power transmission line inspection, and effectively reduces power consumption of the ground station.

\section{Reference}

1. Zhou Xiangsheng. Overview of UAV TT \& $\mathrm{C}$ and instructions transmission technology[J]. TT \& C, remote sensing and navigation, 2008, 38 (1): 30-33

2. Fang Guojun, Wang Haitao, Luo Qiufeng, et al. Design of serial communication program for flight control system of a small UAV[J]. Computer measurement and control, 2007, 15 (12): 1850

3. Fang Guojun, Wang Haitao, Luo Qiufeng, et al. Design of serial communication program for flight control system of a small UAV[J]. Computer measurement and control, 2007, 15 (12): 1850

4. 3D reconstruction of power line from Airborne LIDAR point cloud of overhead transmission line[J] Lin Xiangguo, Zhang Jixian. Journal of Surveying and mapping. 2016 (03)

5. Automatic route optimization of unmanned helicopter power line inspection [J]. Xie Xiaowei, Peng Xiangyang, Liu Zhengjun, Mai Xiaoming, Zuo Zhiquan, Wang Ke. Surveying and mapping science. 2015 (08)

6. Application of LIDAR point cloud in power line inspection [J]. Hou Guorui. Jingwei Tiandi. 2019 (04) 